Published in Young Consumers by Emerald. The original publication is available at: https://doi.org/10.1108/YC-07-2019-1020. This article is deposited under the Creative Commons Attribution Non-commercial International Licence 4.0 (CC BY-NC 4.0). Any reuse is allowed in accordance with the terms outlined by the licence (https://creativecommons.org/licenses/by-nc/4.0/). To reuse the AAM for commercial purposes, permission should be sought by contacting permissions@emeraldinsight.com

\title{
Slogans, Brands and Purchase Behaviour of Students
}

\author{
Maria Rybaczewska, \\ University of Stirling, Stirling, Scotland, \\ University of Social Sciences, Lodz, Poland, \\ Siriphat Jirapathomsakul, \\ Cosmo Group Public Company Limited, Bangkok, Thailand
}

Yiduo Liu, Industrial and Commercial Bank of China Hubei Province Branch, Hubei, China

Wai Tsing Chow, University of Stirling, Stirling, Scotland

Mai Thanh Nguyen, Ho Chi Minh, Vietnam,

Leigh Sparks, University of Stirling, Stirling, Scotland, Stirling Management School Marketing and Retail Divsion FK9 4NT Stirling, Scotland, United Kingdom

\section{Abstract}

Purpose: The aim of this paper is to extend the understanding of the influence of slogans (e.g.

"Dare for More") on brand awareness and purchase behaviour of students.

Design/methodology/approach: Data were collected thorough 34 in-depth face-to-face interviews with university students, using the Customer Decision Process (CDP) model as an approach.

Findings: Our research confirmed that conciseness, rhythm and jingle are key features strengthening customers' recall and recognition, both being moderators of slogans' power. The role and influence of slogans depend on the stage of the customer decision making process. 
Key influencers remain product quality, popularity and price, but appropriate and memorable slogans enhance products' differentiation and sale.

Practical implications: Our findings deliver a particular justification for marketers not to promise young consumers too much through slogans, as this leads to too high expectations adversely influencing their post-purchase feelings. During the Information Search, slogans can create or strengthen or weaken the willingness to buy the advertised product, depending on the slogan, thus emphasising the need for care over slogan design and use.

Originality/value: This research expands the understanding of slogans and brand awareness from the perspective of their impact on purchase behaviour. Our results revealed that the model approach to shopping behaviour does not confirm the belief that slogans influence consumers the most during the phase of Evaluation of Alternatives. Slogans provide a reference point for young consumers to decide whether they are satisfied or dissatisfied with their purchase during the Post Purchase phase and provide information during the Information Search phase. Our results add to the literature in terms of the criteria determining consumers' recognition and recall of slogans.

Keywords: slogans, brands, purchase behaviour, customer decision process (CDP) model, students, young consumers.

\section{Introduction}

Retail markets provide consumers with a large variety of similar purchase alternatives. Companies attempt to differentiate their products and to communicate key benefits of their brands. One method of doing this is by the use of slogans (Kohli et al., 2007). A slogan is understood as a specific product 'label' that consumers can memorise and recite (Wesseloo, 
2015). A slogan is a core component of a brand, introducing dynamics and increasing brand equity in an effective and convenient way i.e. it makes the brand special and acts as a useful hook, helping customers understand the meaning of the brand (Bovée and Arens, 1992). A slogan and a logo are two elements essential for improving brand identity (Kohli et al., 2013). A slogan also plays a role in delivering messages for brand building in customers' minds. If a business develops a positive and memorable slogan, they can gain an advantage in customers' minds and potentially enhance customers' loyalty. The objective of developing a slogan is to facilitate customers' information memory towards a brand and information concerning that specific brand (Reece, 1984). Consequently, as slogans are tools to grab consumers' attention and deepen their memory about brands (Michalik and Michalska-Suchanek, 2016), they help customers recall and recognise particular brands (Cheema et al., 2016).

While various studies emphasise the importance of advertising slogans, Jun and Lee (2007) suggested that further study of slogans and brands could be targeted at consumer purchase behaviour and advertising strategies. This study contributes to this wider understanding of the role of slogans and brands in purchase behaviour.

This investigation aims to identify young consumers' perception of the influence of slogans on their purchase behaviour. Using the Customer Decision Process (CDP) model we explore the stages when slogans gain and/or lose importance/decisive power. Treating customer's recall and recognition as moderators of slogans' influence on purchase behaviour, this paper investigates the features of slogans, determining their power. Since we believe consumers' awareness in most cases does not differentiate slogans, jingles and 'earworms', we treat slogans as a wider concept incorporating these elements. We thus investigate the specific characteristics of slogans determined by the respondents.

Following this brief introduction the literature review discusses key interdependencies between slogans, brand perceptions and brand equity, followed by slogans and recall aspects, 
accompanied by slogan and purchase behaviour issues. The final section of the literature review refers to the CDP model approach towards purchase behaviour. The methodology starts with the research approach and continues with the rationale for the chosen slogans and the research procedure description. The results and discussion address consumers' recall and recognition issues, followed by the findings on the CDP model approach and consumers' purchase intention. Finally, after discussing our conclusions, we reflect on limitations and future research.

\section{Literature review}

2.1. Slogans, brand perception and brand equity

Keller (2008) claimed that a slogan is a short phrase that conveys descriptive or persuasive information about the brand. Slogans can be functional tools that bundle a brand and products together and play an important role in packaging and marketing plans. In other words, they have a direct and positive impact on brand perception (Cheema et al., 2016), e.g. the case of Kit Kat's slogan ("Have a break, have a Kit Kat") investigated by Micael and Sara (2005).

Strong branding is closely related to brand awareness, loyalty, identity and word-ofmouth marketing, all highly influencing brand equity (Anselmsson, Bondesson, and Melin, 2016; McGowan, Shiu, and Hassan, 2017; Ryan and Casidy, 2018). The image of a brand is the key driver of brand equity, which refers to consumers' perception and feelings about a brand and influences consumer behaviour (Kristensen, Gabrielsen, and Zaichkowsky, 2012; Laforet, 2011; Zhang, 2015). Therefore, knowledge about customers lets businesses adjust marketing strategies to maximise the power of messages for target audience. From a business point of 
view, brand perception significantly affects consumers' choices and decisions in the marketplace. To young consumers, branding and integrated marketing communication with new approaches can strengthen their relationship with the brands (Lazarevic, 2012). Branding firmly associates with generation Y's self-expression need (Rajamma et al., 2010).

A slogan is amongst the factors affecting consumers' brand perception, and consequently brand equity. Abdi and Irandoust (2013) claim that slogans can enable the company to introduce itself and its products or services. In order to encourage positive brand perception and high brand equity, companies focus on creating a simple and memorable slogan, which consumers can easily associate with this specific brand or product (Abdi and Irandoust, 2013).

\subsection{Slogan and purchase behaviour}

A slogan is a bridge to convey the product or brand attributes to the consumer in a short phrase. It can let consumers know the product or brand attributes, features and identity, which can stick then in consumers' mind for a period of time (Cheema et al., 2016). Likewise, slogans help to boost brand awareness, recall and heighten brand recognition (Pryor and Brodie, 1998).

Kohli et al. (2013) implied that the message a slogan conveys brings a brand closer to the consumer and makes it more attractive. They asserted that it is important to sustain slogans and not change them often. Slogans such as McDonald's, "I'm lovin' it", Subway "Eat fresh", and KFC “It's Finger Lickin' Good!” have been in use for a long time. Hence, Laran et al. (2011) claim that slogans and brands belong to persuasion strategies, with consumers acknowledging the role of slogans through their purchase behaviour.

Slogans contain short words which are mainly used to recall something about brands (Miller and Toman, 2015). A slogan can also strengthen brand positioning and associations and 
promote the brand itself (Pryor and Brodie, 1998). The slogan is used to promote the company's progress and a catchy slogan makes consumers recognise the brand (Timothy, 2001). An effective slogan will not only stay in the consumers' mind but also potentially enhance their mood, strengthening connections between brands and consumers (Dahlén and Rosengren, 2005). Consumers will recall the slogans' value, and create a deeper remembrance and a psychological feeling towards the brands. Timothy (2001) stated that "The more the lines resonate with the big ideas, the more memorable it will be". When consumers see a slogan, they think of the brand if that slogan's message suggests or links with the brand's value and key advantages. Brand awareness, however, does not always lead to brand loyalty (Syrett and Lamminman, 2004), especially in the case of young consumers. Millennials are different from previous generations in their shrewdness about what and how they are being sold to (Syrett and Lamminman, 2004). Their purchase behaviour is driven by particular visions, dynamics and styles of self-expression within socio-cultural processes (Santisi et al., 2014).

A slogan is one of the tools increasing the customers' awareness of a brand. However, the process of creating and evaluating a slogan is complicated. Determining why and how slogans affect the customers' mind is a complex task. There are contradictory research findings. While Abdi and Irandoust (2013) claim that customers' recognition of slogans can be positively influenced by the slogan's simple structure, Balmer and Greyser (2006) state that the complexity of slogans makes people recognise and remember them deeply. On the other hand, Kohli et al. (2013) show that features of a slogan such as complexity, jingles and rhymes have no impact on slogan recall. Instead, high spending i.e. repetition and regularity is the way to make consumers recall a brand's slogan. In such a case, the slogan has to be retained rather than changed over time.

These inconsistences suggest a gap in knowledge, which we address. Despite the studies already conducted, there is a need for further exploration. Importantly, customers' 
perception of slogans can affect their prospective purchase decision. It is necessary for brands and marketers to identify and understand the factors influencing consumers' purchase behaviour in order to develop their marketing message. Consequently our first research question is:

RQ1: What is the impact of slogans on purchase behaviour?

Dahlén and Rosengren (2005) noted that consumers will use their "constructive memory" to connect slogans with brands when a brand name is not given. Less complicated slogans are easier to recall than complicated ones (Miller and Toman, 2015). Slogans are important in creating the brand but recall is the most efficient measure of the slogan's achievement. Therefore, treating recall and recognition as moderators of slogans' power on purchase behaviour, we ask whether features are triggers or deactivators of customers' recall and recognition. We investigate factors/mechanisms minimising or maximising the potential role of slogans described in the literature. Thus, the second research question is:

RQ2: How do slogans affect consumers' recall and recognition?

2.3. The customer decision process - model approach

Marketers try to understand the customers' buying process stage by stage. There is a commonly agreed five phase customer decision process (CDP) model (Munthiu, 2009) consisting of: Problem Recognition, Information Search, Evaluation of Alternatives, Purchase Decision and Post Purchase Behaviour (Figure 1).

Problem Recognition is a stage when customers' needs can be influenced by both internal and external stimuli (Munthiu, 2009). In a competitive market, people can be confused by dozens of almost identical products. That is why consumers engage with the next two phases of Information Search and Evaluation of Alternatives. During Information Search consumers 
explore available options of the required product. This includes internal and external searching - the key here is to figure out how prospective customers consider information (Munthiu, 2009). Following Munthiu (2009), "internal search" means information search activity in the customer's own memory, whereas "external search" refers to external sources of information such as family and friends or commercial tools such as sales people or television advertising. Evaluation of Alternatives is a stage when different choices for the desired product or the service are considered. It is a complex stage when an individual analyses many factors such as personal experience, the role of the service or the product, the consequence of making a poor decision, the intricacy of the alternatives considered or the urgency of making a decision (Munthiu, 2009). Bettman (1982) described this process as based on advantages and disadvantages of the alternatives. Acquiring a certain amount of information and considering different alternatives, a consumer is eventually willing to make a trade-off, which happens in the Purchase Decision stage. At this moment, all of their considerations, assessments or judgements become concrete helping them make a final decision on what they choose to buy. The whole CDP ends with the Post Purchase Behaviour phase, when the consumers give assessments on their purchase decision, usually on the basis of the correlation between their expectations and the product's perceived performance, which leads to satisfaction or the lack of thereof (Munthiu, 2009).

There is however a gap in knowledge concerning the CDP stage or stages when a slogan is the most influential and meaningful for consumers' purchase behaviour. Despite wide theoretical implications and managerial applications, the literature does not identify the role of slogans within the CDP stages. It is not clear at what CDP stage slogans play the most substantial or influential role. Each CDP stage results in different customers' needs and sensitivity to both external and internal stimuli. Therefore we address the relationships between widely understood slogans and customers behaviour at particular stages of the purchase 
decision making process. We focus on consumers' perception on the influence/power of slogans on the particular CDP stage of their purchase behaviour. Consequently the third research question is:

RQ3: At which stage of CDP are slogans most influential?

\section{Methodology}

3.1. Research approach

The objectives of this research led to the choice of an interpretive approach. The commonly known CDP model has a relative lack of complexity (participants effortlessly can grasp it), enabling the separate analysis of its 5 distinctive stages. To acquire information about how consumers think about slogans we applied the model discussed by Khalid and Yasmeen, 2017 - "Three M's of Slogans" (i.e. Meaningful, Motivate and Memorable). Additionally, the relationship between brand equity and advertising slogans of Aaker (1991; cited in Abdi and Irandoust, 2013; p.63-64) was adopted.

To make our research insightful we aimed to contextualise it within a sector which is commonly known and very active in terms of marketing campaigns using slogans. Therefore we focus on the food and drink sector, and specifically soft drinks - products present in everyday life. Anon (2018) mentioned that soft drinks delight people's taste buds and are easily found everywhere (from vending machines or fast-food chains to supermarket checkouts). Additionally, soft drink companies frequently release new promotions and campaigns to attract consumers.

The main focus of this study is the subjective point of view of respondents concerning the slogans, their power and role during CDP. Whilst quantitative research can provide 
generalizable results, our priority is to disentangle the topic's multidimensional and complex character. Therefore a qualitative approach offering a more elaborate narration (Malhotra, 2015) was required. Qualitative methods are the most beneficial to reveal the subjective point of view of consumers addressed by this research (Bryman and Bell, 2015). Additionally the qualitative method was selected as our primary research method due to its elaborate narration capability in a given context (Malhotra, 2015). As a result to answer the research questions (RQ1, RQ2, RQ3), semi-structured face-to-face interviews were conducted. They enable both structured and open sections, investigating issues in depth.

The focus of the study is on young consumers as we wished to investigate the issues within a controlled segment of the population. A segmentation rather than a whole population approach is likely to yield more informative results. Younger consumers were chosen as they are the target market for our product/sector and are a segment receiving more stimuli such as slogans from a wide variety of sources/channels.

Within the younger consumers context, university students were chosen as the respondents for our study for several reasons. Firstly, the effects of advertisements on consumer behaviour has been studied previously in the context of students (for example by Bashir and Malik (2009) and Seliga and Chmielecki (2012)), so there is a track record in this segment. Secondly, the relationship between slogans and the purchase decision process has been investigated in that context by Quintal, Phau, Sims, and Cheah (2016). Thirdly, students are often used as samples for younger consumers due to feasibility and practicality, and that they have a breadth of appropriate life experience.

3.2. Rationale for the chosen slogans 
This investigation focused on four slogans: "Open Happiness" and "Taste the Feeling" for Coca-Cola and "Dare for More" and "Refresh Everything" for Pepsi. In 2017, all variants of Coca-Cola and Pepsi ranked just after Private Label among leading soft drink brands in the United Kingdom (Nielsen, 2017). The slogans are short, memorable and easy to repeat (Bovée and Arens, 1992). Three further characteristics can be distinguished. Firstly, hyperbole, a rhetorical figure for exaggeration, which purpose is to emphasise product qualities and intensify the imagination and emotion (Michalik and Michalska-Suchanek, 2016), such as "Refresh Everything" for Pepsi. There is nothing that can refresh all things at one time with one product. Secondly, 'Imperative mood', a natural persuasion. It is used to recommend/suggest something/doing something in a form of a promising command or request (Michalik and Michalska-Suchanek, 2016) such as "Refresh Everything” for Pepsi and "Open Happiness" for Coca-Cola. These slogans aim to highlight the product's features and benefits. Thirdly, 'Verbs', which may enhance the message vitality and boost the slogan power of persuasion, here "Refresh Everything" and "Dare for More" for Pepsi, "Taste The Feeling" and "Open Happiness" for Coca-Cola. These slogans begin the phrases with the verb which not only grabs the attention, but also lets the audience focus on what the designers emphasise about the product (Michalik and Michalska-Suchanek, 2016).

\subsection{Research procedure}

All interviews were conducted at a Scottish University campus. The number of individual interviews was decided by saturation criteria (Creswell, 1998; Bryman and Bell, 2015). To reach saturation we interviewed 34 students. Participants were recruited through a range of communication channels, including social media, word-of-mouth marketing, advertisements around the university campus (21 respondents in total) and personal contacts 
(13 persons). There were no incentives offered. Personal recruitment via overlapping social media and channels provided a positive context for engagement. All interviews were face-toface and semi-structured, and conducted between June and August 2018. The aim was to explore the students' personal attitudes and experience about slogans in general and the chosen slogans in particular. Different tests (recall test, recognition test, emotion test, evaluation test and (competitive) differentiation test) were adopted to obtain the full picture of the power of slogans from the participants' viewpoint. We asked about this power in the context of the particular stages of CDP.

We intended to reach an ethnically diverse group of young adults (following Creswell (1998)). Consequently we recruited 15 male and 19 female participants aged 20-35 coming from both European (13 participants) and non-European (21 participants) countries (China, the United Kingdom, India, Vietnam, Greece, Pakistan, Germany, Thailand, etc.). The topic and context awareness required among the participants was such that we sought both undergraduate and postgraduate students. Reaching the saturation criteria was our priority compromised a little by challenges such as our decision not to provide incentives and the time of year which meant we interviewed 9 undergraduate but 25 postgraduate students. All respondents were anonymised and interviews were voice-recorded.

We then undertook a thematic analysis of the collected information. Following the research objectives, questions and literature discussed in the literature review section of this paper, five main themes were created (Figure 2). This was done separately initially and then cross-checked by the team of authors. Researchers transcribed all interviews and ordered the information according to the created themes. The richness of data enabled in-depth investigation of all themes separately before undertaking combined analysis required to answer the research questions (RQ1, RQ2, and RQ3). 


\section{Results and discussion}

\subsection{Young Consumers' recall and recognition}

In terms of the slogans' popularity, those of Coca-Cola ("Taste the Feeling" and "Open Happiness") were the favourite twice as often as those of Pepsi ("Dare for More" and "Refresh Everything"). Most of the participants perceived these slogans as catchy and easy to remember. The vast majority agreed that the slogans show the brands' and/or the products' attributes. Moreover, 24 out of 34 participants stated that slogans in general could show a brand's and/or a product's attributes. Twenty nine participants admitted that the slogan is an influential tool for a brand.

\subsubsection{Young Consumers' perception of the power of slogans}

Thematic analysis showed that conciseness, rhythm and jingle are the predominant features that consumers recall concerning slogans (11, 9 and 8 participants respectively). "...Maybe jingle and rhythm. Rhythm is one of the features in a slogan I can rememeber." (Participant 19). "Jingle may be the only thing I can recall. By the way, short slogans are more memorable for me" (Participant 32). Such observations correspond with the literature. Our participants consistently perceived slogans as an influential tool for memorising a brand or a product and a sign of the brand value. Participant 34 stated: "When you have a slogan and it is the successful one, people will remember it and memorise it, so they automatically memorise your product."

The majority of participants (19 persons) emphasised that a creative and unique slogan can make a brand stand out from similar competitors. Many of them like the verb "Open" in the slogan "Open Happiness" as it is connected to the action of opening a can of Coca-Cola. 
"Because it presents in a good way like 'Open Happiness' when I open it I think both the commercial that is if you open it, the happiness will come out." (Participant 2). A distinctive slogan is believed to create a unique brand identity which roots itself in consumers' mind. "...because there's only one slogan for a brand. There's no slogan for two products something like that so it distincts a lot." (Participant 2).

\subsubsection{Young Consumers' memory of chosen slogans}

Analysis revealed that consumers tend to connect with the emotions and feelings contained in slogans. Being asked about their memory of Coca-Cola and Pepsi's chosen slogans, 15 participants could remember accurately Coca-Cola's slogans whilst only 1 person remembered Pepsi's slogans. Many of them thought that Coca-Cola's slogans implied a "feeling". As Coke sells "happiness" in a bottle rather than a drink, Coca-Cola was believed to provide an "experience" and "lifestyle" associated with the products. Connecting with feelings, slogans help to enhance consumers' recall process. Indeed, most participants inclined to CocaCola's slogans when it came to giving personal opinions on the slogans most connected to the brands. A slogan implying a feeling can give a sense of linkage between its brand and consumers' perspective. It was also pointed out that Coca-Cola's message is more inwardlooking whereas Pepsi's message is more outgoing. "But both Coca-Cola brandings refer to emotion, 'Happiness' and 'Feeling'; and Pepsi is all about being adventurous." (Participant 8).

\subsection{The Customer Decision Process Model}

\subsubsection{The preference, purchase habit and motivation to buy soft drinks}

Thematic analysis emphasised the literature that adverts encourage customers to buy products as an external stimulation in CDP. The participants admitted that they did not pay 
much attention to slogans, yet recalled them through watching television commercials. Young customers recognise a slogan and tend to buy the product if the advert suggests an attractive content. During the interviews, Nike's slogan "Just Do It" was mentioned a great number of times as a typical example of effective slogans. "Like if I buy shoes from Nike, 'Just Do It' appears in your mind like pushing you to do do something." (Participant 12). Participant 2 implies that he recalls slogans while buying his favourite product i.e. Red Bull "Sometimes I thought for the Red Bull's slogan then I ah I got it.”.

Additionally many psychological and social factors are included in an individual's motivations to buy a soft drink. Within the frame of Coca-Cola and Pepsi, thirst and taste are the internal stimuli which influence consumers' purchase behaviour the most (10 and 11 participants respectively). As stated by Munthiu (2009), people are driven by human basic needs as an internal stimulation and it becomes one of the influencing factors for customers in the Need Recognition phase of CDP. "Yeah I think thirsty and I think I need some cold drinks. I think it's a basic motivation to buy" (Participant 11). Quality, price and popularity are the key external drivers for participants to buy a product. They also differentiate a specific brand from other alternatives in a broader context of other markets. Advertising and packaging were also often mentioned.

\subsubsection{The influence of slogans on consumer purchase behaviour}

This theme confirmed the statement frequently discussed in the literature that a slogan can affect customers at all stages of CDP. To examine how slogans have an impact on consumer purchase behaviour, participants were told to select one noticeable stage through the CDP. The data demonstrated that most participants (31\%) believe that Information Search is essential, followed by the Post Purchase Behaviour stage (25\% of participants), Need Recognition (19\%), Purchase Decision and Evaluation of Alternatives (both selected 13\%). While searching for the 
appropriate information, participants found slogans a useful and valuable source. According to participant 4: "I just need the product but I'm not sure which one I should buy, so if I just think of any slogan that's attractive to me, so I'm gonna buy that instead of other ones... Even when at the start of Information Search maybe there are 5 or 6 alternatives but I'm just thinking about 2 alternatives. It means that there are gonna be several rounds for me to choose the information. Sometimes I wil not search every alternatives that I have, sometimes I just only choose 2 most attractive alternatives, so I think Information Search even is more important than Alternatives stage".

Slogans play different roles for the participants in the context of Post Purchase Behaviour stage. They compared a slogan content with their perception of the product quality. In other words, they linked their experience with what the brand promised. "You can show a screen about how good the product is to someone who has never had it before or has never bought it before, but they won't believe you until after" (Participant 8).

Slogans were also perceived as powerful in the context of Need Recognition, which adds another dimension creating the demand. Participants choosing Need Recognition tend to choose a brand or a product if an interesting slogan is given as an external stimuli to them. "Recognition because slogan might be effective when a consumer is knowing nothing about a product, words might catch their attention." (Participant 18). Their responses indicate that this behaviour happens primarily in the case of new brands or products. Otherwise, they pay attention mostly to the product characteristics including price, quality and packaging. This observation corresponds with the focus of this study, with very close and comparable competitors (Coca-Cola and Pepsi) searching for some additional sources of competitive advantage i.e. intangible criteria including remarkable and catchy slogans.

4.3. Young consumer's purchase intention 


\subsubsection{The preference, purchase habit and motivation of soft drinks}

Not unexpectedly, thematic analysis showed that quality, popularity and price are the most influential factors for consumers to choose a specific brand. Among various psychological and social factors such as thirst, taste, sugar rush, energy boost, refreshment, social etc. some factors are dominant in manipulating customer purchase behaviour. Taste, popularity and price were the most commonly underlined by the participants. "Because of its brand and price I think. I always take these two factors for consideration when I buy soft drinks." (Participant 5). "Among all the cold drinks, the taste and the cool feeling Coke gives me is the main reason why I choose it." (Participant 32). As the majority of participants explained their preferences in the context of Coca-Cola and Pepsi, taste can be interpreted as quality, i.e. consumers pay most attention to a product quality, popularity and price. Packaging also influences consumer purchase decision to a significant extent.

\subsubsection{Young consumers' perception of the power of slogans}

This theme confirmed the literature that an attractive slogan can be effective tool for sales if the alternatives are equivalent on quality, popularity and price. Around half of the respondents (18 out of 34 people) did not think slogans could have an effect on their purchase decision as they mostly consider other features of a product such as price and quality. However, the other half claimed that an appealing slogan can remind them of the product. Particularly with two products which are both popular, trustworthy and with little difference between price and quality, participants believe that slogans could help them to make a final decision. "I'm gonna rememeber when I have 2 identical products, so which slogan or which brand I feel more familiar, I'm gonna buy that product." (Participant 4). 


\subsubsection{The influence of slogans on young consumer purchase behaviour}

This theme revealed that an attractive slogan can make young consumers switch their purchase behaviour to another brand. Many participants claimed that slogans could not encourage them to buy a product. Nevertheless, we kept examining this result by asking whether they were more or less likely to buy Coke or Pepsi after taking the given slogans into consideration. It was then revealed that over one third of participants decided to buy the particular product just because of the slogan they liked more. "Before I know their slogans, I would like to buy Pepsi because I think the taste is better, but when I saw their slogans, I want to buy Coca-Cola because it's better." (Participant 7).

\section{Conclusions}

Our research contributes to the understanding and reconciliation of contradictory opinions in the literature concerning customers' recognition of slogans. We showed that particular features of slogans can improve consumers' recall and memory of the brands, i.e. conciseness, rhythm and jingle (RQ2). Additionally, a slogan with creative content or unique design has the potential to quickly capture consumers' attention. A unique brand identity can be encouraged by slogans supporting brand differentiation.

Apart from slogans' content, emotional connection was an important element attracting young adult customers, including their final purchase decisions (RQ1). Slogans which connote positive attitudes and feelings can deepen consumers' memory and perception towards the brand. In the case of the soft drink market, we found that Coca-Cola impresses young consumers with a classic and inward-looking image; whilst Pepsi is commonly considered as an outgoing brand. With the brand value measured by emotional connection, Coca-Cola was remembered much more by the participants. 
The third research question (RQ3) revealed that slogans can impact customers' minds during all the stages of CDP. If a slogan sounds interesting enough, customers can be motivated to pay more attention to the product or the brand despite the lack of their previous knowledge of the product or the brand. Slogans become then an external stimulation for customers in the Need Recognition phase. A key role of slogans however occurs in the Information Search and Post Purchase phases. While searching for information, slogans encourage customers to get to know more about the brand/product they might purchase. During the Post Purchase phase many participants tend to link their purchase experience and the product's attributes advertised by slogans' content, treating it as a promise of what the product offers. Evaluation of Alternatives was not strongly noted by the participants in the context of slogans' power and the Purchase Decision stage was hardly mentioned.

This research contributes to expanding the understanding of slogans and brand awareness from the perspective of their impact on purchase behaviour. We addressed the inconsistencies in the literature concerning e.g. customers' recognition of slogans and contextualised slogans within the CDP model. Our results revealed that this model approach to shopping behaviour does not confirm the belief that slogans, increasing brand awareness, are the most meaningful and consequential in the Evaluation of Alternatives phase. Slogans are rather a reference point for young consumers to decide whether they are satisfied or dissatisfied with their purchase during the Post Purchase phase. They also provide meaningful information within the Information Search phase. Slogans can create or strengthen the willingness to buy the advertised product or just the opposite, depending on the slogan. Our findings deliver a justification for marketers not to promise too much through slogans, as this leads to excessive expectations adversely influencing the post-purchase feelings of consumers.

\section{Limitations and future research}


We acknowledge potential limitations resulting from possible bias concerning both participants and researchers, connected to limited objectivism, dynamics of preferences, interpretation of declarative data etc. (Palmatier, 2017; Maxwell, 2013; Blockeel, 2018).

This study suggested the need for further exploration of slogans, brands and purchase decision relationships. We believe that the Information Search and Post-Purchase phases of the CDP deserve separate and more in-depth investigation, especially from the perspective of different types of purchase decisions and particularly impulse purchases. We also postulate dissimilarities between purchases of luxury and everyday products in terms of both slogans' overall impact on purchase behaviour and slogans' power on particular phases of CDP (especially Information Search and Post- Purchase).

Research on consumer behaviour amongst young adults requires a comprehensive understanding of this segment's attributes. Their technological powers ('digital natives') define them as a different generation from their parents (Solomon et al., 2006 cited in BilinskaReformat and Stefanska, 2016) which leads to their distinct behaviour and attitudes. The need for deeper investigation on the association between young consumers' purchase behaviour, slogans and digital literacy is a task for the future.

\section{References}

Abdi, S. and Irandoust, A. (2013) The Importance of Advertising Slogans and their Proper Designing in Brand Equity. International Journal of Organizational Leadership, 2 (2), pp. 62-69. 
Anon. (2018) 8 Reasons Why People Drink Soda \& 16 Reasons To Give Up Soda Drinking. eMedExpert.com. Available at: www.emedexpert.com/tips/soft- drinks.shtml, [Accessed: 17 May 2019].

Anselmsson, J., Bondesson, N., and Melin, F. (2016) Customer-based brand equity and human resource management image: Do retail customers really care about HRM and the employer brand? European Journal of Marketing, 50 (7/8), pp. 1185-1208.

Balmer, J.M.T. and Greyser, S.A. (2006) Corporate marketing. European Journal of Marketing, 40 (7/8), pp. 630-641.

Bashir, A. and Malik, N.l. (2009) Effects Of Advertisement On Consumer Behavior Of University Students. Proceedings 2nd CBRC, Lahore, Pakistan.

Bettman, J.R. (1982) A Functional Analysis of the Role of overall Evaluation of Alternatives in Choice Processes. Advances in Consumer Research, 9 (1), pp. 87-93.

Bilinska-Reformat, K. and Stefanska, M. (2016) Young Consumers' Behaviours on Retail Market and Their Impact on Activities of Retail Chains. Business Excellence, 10 (2), pp. 123 135.

Blockeel, H. (2018) Declarative data analysis. International Journal of Data Science and Analytics, 6 (3), pp. 217-223. 
Bovée, C.L. and Arens, W.F. (1992) Contemporary advertising. [Book] 4th ed. Illinois: Homewood.

Bryman, A. and Bell, E. (2015) Business research methods. Oxford University Press, USA.

Cheema, F-E.A., Rehman, S., Zia, S., and Rehman, M.U. (2016) Do Taglines Have A Positive Impact On Building The Brand Perception? A Case Study On Kit Kat. Journal of Business Studies, 12 (1), pp. 52-64.

Buil Creswell, J.W. (1998) Qualitative inquiry and research design: Choosing among five traditions. Thousand Oaks, California: Sage Publications.

Creswell, J.W. (1994) Research Design: Qualitative \& Quantitative Approaches. Thousand Oaks, California: Sage Publications.

Dahlén, M. and Rosengren, S. (2005) Brands affect slogans affect brands? Competitive interference, brand equity and the brand-slogan link. Journal of Brand Management, 12 (3), pp. 151-164.

Jun, J.W. and Lee H-S. (2007) Cultural differences in brand designs and tagline appeals. International Marketing Review, 24 (4), pp. 474-491.

Keller, K. (2008) Strategic Brand Management. 3rd ed. New Jersey: Prentice Hall. 
Khalid, R. and Yasmeen, T. (2017) Effect of Advertising Slogans on Consumer Purchase Intention in Pakistan. J. Basic. Appl. Sci. Res., 7 (4), pp. 25-33.

Kohli, C., Leuthesser, L., and Suri, R. (2007) Got slogan? Guidelines for creating effective slogans. Business Horizon, 50 (5), pp. 415- 422. Doi: 10.1016/j.bushor.2007.05.002. Available at: https://www.sciencedirect.com/science/article/pii/S0007681307000730 [Accessed: 25 June 2019].

Kohli, C., Thomas, S., and Suri, R. (2013) Are You In Good Hands? Slogan Recall: What Really Matters. Journal of Advertising Research, 53 (1), pp. 31-42.

Kristensen, T., Gabrielsen, G., and Zaichkowsky, J.L. (2012) How valuable is a well-crafted design and name brand?: Recognition and willingness to pay. Journal of Consumer Behaviour, $11(1)$, pp. 44-55.

Laran, J., Dalton, A.N., and Andrade, E.B. (2011) The Curious Case of Behavioral Backlash: Why Brands Produce Priming Effects and Slogans Produce Reverse Priming Effects. Journal of Consumer Research, 37 (6), pp. 999-1014.

Laforet, S. (2011) Brand names on packaging and their impact on purchase preference. Journal of Consumer Behaviour, 10 (1), pp. 18-30.

Lazarevic, V. (2012) Encouraging brand loyalty in fickle generation Y consumers. Young Consumers, 13 (1), pp. 45-61. 
Malhotra, N.K. (2015) Essentials of Marketing Research: A Hands-On Orientation. 1st ed. Essex: Pearson Education.

Maxwell, J.A. (2013) Qualitative Research Design: An Interactive Approach. 3rd ed. Los Angeles: Sage. Available at:

https://books.google.co.uk/books?id=xAHCOmtAZd0C\&lpg=PP1\&dq=Maxwell\%2C\%20J. A.\%20(2005).\%20\%22Qualitative\%20Research\%20Design\%3A\%20An\%20Interactive\%20 Approach\&hl=zh-TW\&pg=PP1\#v=onepage \&q\&f=false [Accessed: 11 July 2019].

McGowan, M., Shiu, E., and Hassan, L.M. (2017) The influence of social identity on value perceptions and intention. Journal of Consumer Behaviour, 16 (3), pp. 242-253.

Micael, D. and Sara, R. (2005) Brands affect slogans affect brands? Competitive interference, brand equity and the brand slogan link. Journal of Brand Management. 12 (3), pp. 151-164.

Michalik, U. and Michalska-Suchanek, M. (2016) The Persuasive Function of Rhetoric in Advertising Slogans. Journal of Accounting \& Management, 6 (1), pp. 45-58.

Miller, D.W. and Toman, M. (2015) An Analysis of the Syntactic Complexity in Service Corporation Brand Slogans. Services Marketing Quarterly, 36 (1), pp. 37-50.

Munthiu, M.C. (2009) The buying decision process and types of buying decision behaviour. Sibiu Alma Mater University Journals. Series A. Economic Sciences, 2 (4), pp. 27-33. 
Nielsen (2017) Leading soft drink brands ranked by grocery sales volume in the United Kingdom in 2017 (in million litres). United Kingdom: Statista. Available at: https://www.statista.com/statistics/296666/soft-drink-brand-ranking-in-the-united-kingdomuk-by-grocery-sales-volume/ [Accessed: 8 August 2018].

Palmatier, R.W. (2017) Marketing Strategy: Based on First Principles and Data Analytics. Palgrave; 1st ed. pp. 35-89.

Pryor, K. and Brodie, R.J. (1998) How advertising slogans can prime evaluations of brand extensions: further empirical results. Journal of Product \& Brand Management, 7 (6), pp. 497.

Quintal, V., Phau, I., Sims, D., and Cheah, I. (2016) Factors influencing generation Y's purchase intentions of prototypical versus me-too brands. Journal of Retailing and Consumer Services, 30, pp. 175-183.

Rajamma, R.K., Pelton, L.E., Hsu, M.K., and Knight, D.K. (2010) The Impact of Consumers' Need for Uniqueness and Nationality on Generation Y's Retail Patronage Behaviors: Investigating American and Taiwanese Consumers. Journal of Global Marketing, 23 (5), pp. $387-410$.

Reece, B.B. (1984) Children's Ability to Identify Retail Stores from Advertising Slogans. Advances in Consumer Research, 11 (1), pp. 320-323. 
Ryan, J. and Casidy, R. (2018) The role of brand reputation in organic food consumption: A behavioral reasoning perspective. Journal of Retailing and Consumer Services, 41, pp. 239247.

Rybaczewska, M. (2017) General Image of the Telecommunications Companies-Its Determinants and Components. Przedsiebiorczosc i Zarzadzanie, 18 (2, cz. 2 Zarządzanie humanistyczne i publiczne), pp. 293-309.

Santisi, G., Platania, S., and Hichy, Z. (2014) A lifestyle analysis of young consumers: A study in Italian Context. Young Consumers, 15 (1), pp. 94-104.

Seliga, R. and Chmielecki, M. (2012) International marketing in higher education-a comparison study between students' choices in Poland and the UK. Journal of Intercultural Management, 4 (4), pp. 94-101.

Syrett, M. and Lamminman, J. (2004) Advertising and millennials. Young Consumers, 5 (4), pp. 62-73.

Timothy, R. (2001) The Art and Science of the Advertising Slogan. ADSlogans Unlimited, p. 4.

Zhang, Y. (2015) The Impact of Brand Image on Consumer Behavior: A Literature Review. Open Journal of Business and Management, 3, pp. 58-62. Available at: https://file.scirp.org/pdf/OJBM_2015011615441425.pdf [Accessed: 27 January 2019].

Wesseloo, D.M. (2015) The reflection of core values in a company's logo and slogan - An experimental study. Available at: 
http://theses.ubn.ru.nl/bitstream/handle/123456789/2222/Wesseloo,_D.M._1.pdf?sequence=1 [Accessed: 2 July 2019]. 